\title{
Prevalence of burnout among doctors in teaching hospitals in Galle Sri Lanka
}

\author{
A. VD L. A. Vithanage ${ }^{1}$, P. V. De Silva ${ }^{2}$, J. D. V. C. Lekamwasam ${ }^{3}$ \\ ${ }^{1}$ Acting Consultant Physician, DGH Monaragala, Monaragala, Sri Lanka \\ ${ }^{2}$ Community Medicine, Faculty of Medicine, University of Ruhuna, Galle, Sri Lanka. \\ ${ }^{3}$ Consultant Physician, TH Karapitiya, Galle, Sri Lanka.
}

\section{Email address:}

dr.lakmalv@gmail.com (A. V. L. A. Vithanage)

\section{To cite this article:}

A. VD L. A. Vithanage, P. V. De Silva, J. D. V. C. Lekamwasam. Prevalence of Burnout among Doctors in Teaching Hospitals in Galle Sri Lanka. European Journal of Preventive Medicine. Special Issue: New Frontiers of Public Health from the Pearl of Indian Ocean, Sri Lanka. Vol. 3, No. 2-1, 2015, pp. 1-4. doi: 10.11648/j.ejpm.s.2015030201.11

\begin{abstract}
Introduction: Burnout is a word used to assess the level of exhaustion or disengagement of a person involve in any particular profession. This topic has come to the light in recent years after the results of several studies showing that there are significant number of professionals is in the "Burnout" category. There are no published study results on this topic in Sri Lanka and it is high time to evaluate the issue in the Country. Method: We included all the professionals employed in the teaching hospitals both Karapitiya and Mahamodara. Data was collected using a self-administered questionnaire called Oldenburg Burnout Inventory (OLBI), well accepted and free to study tool. Results: 155 doctors had completed the questionnaire. Out of this the majority were males; 53.5\%. Majority of the doctors were grade medical officers; $63.2 \%$. Among them there were $24.8 \%$ doctors who were having more than 10 years' experience. $24.2 \%$ doctors were engaged in private practice. A large number of doctors had satisfactory relationship with their Consultant; $94.7 \%$, and with their colleagues; 98.6\%. Most of the doctors had never consumed alcohol and never smoked. Out of all $36.1 \%$ found exhausted and $34.2 \%$ were disengaged with their work. The overall "Burnout" was $20.6 \%$. Doctors involved in private practice are significantly burnout; $\mathrm{P}=0.04$, compared to doctors not doing private practice. In addition the use of alcohol also showed the significant association; $\mathrm{P}=0.04$ with the Burnout". Conclusion: This study highlighted that there is a significant proportion of doctors; $20.6 \%$, who are "Burnout". Therefor further studies are recommended to identify the causes in detail.
\end{abstract}

Keywords: Occupational Health, Doctors, Burnout

\section{Introduction}

Job burnout emerged as an important concept in the 1970s, and it captured something very critical about people's experience with work. It continues to do so today, some 35 years since its introduction to psychological literature and to cultural discourse. Currently, burnout is a well-established academic subject on which thousands of publications have appeared, and about which numerous congresses and symposia are held. We estimate that currently over 6,000 books, chapters, dissertations, and journal articles have been published on burnout $(1,2)$.

"Burnout" is a syndrome of emotional Exhaustion, depersonalization, and reduced personal accomplishment that can occur among individuals who work with people in some capacity" (3), by Maslach, who is a world famous pioneering figure in the field of burnout and the founder of the Maslach burnout inventory (MBI). After its initial emergence in the USA in the 1970s, the concept was introduced in the 1980s in Western Europe, particularly the UK, the Low countries (Holland and Belgium), Germany, and the Nordic countries (Scandinavia and Finland), as well as in Israel. From the mid1990s onwards burnout was also studied in the rest of Western and Eastern Europe, Asia, the Middle East, Latin America, Australia, and New Zealand. Finally, after the turn of the century, research on burnout spread to Africa, China, and to the Indian subcontinent. It is interesting to note that, roughly speaking, the order in which the interest in burnout seems to have spread corresponds with the economic development of the countries involved. For instance, currently, the economies of India and China are booming, and burnout now seems to attract attention in these countries 
as well. It has been suggested that globalization, privatization, and liberalization cause rapid changes in modern working life, such as increasing demands of learning new skills, the need to adopt new types of work, pressure of higher productivity and quality of work, time pressure and hectic jobs, which, in their turn, may produce burnout - particularly in rapidly developing countries like India (4).

Sri Lanka is a recognized country having recent development in almost all kind of professional activities. Health care has gained vast development steps in the recent past. According to the world trend we cannot neglect the fact that the professional burnout is a common association. The importance of identifying the gravity of the Burnout and its associations is that it will help to maintain high professional outcome, which is been done in developed countries in regular manner. There is no valid data found regarding Burnout among medical professionals in Sri Lanka despite multiple issues in the field.

The Oldenburg Burnout Inventory (OLBI), selfadministered questionnaire was used as the study instrument. Which was selected considering the facts like, it is free to use for non-commercial use, internationally validated (5) and easy to answer by the candidate. The questionnaire assesses disengagement and exhaustion as two main features of burnout. It was introduced and studied by Prof. Evanglia Demerouti. In addition to that there were an 11 other questions to assess socio-demographic data, data on occupation related factors at introduction of the questionnaire.

\subsection{Justification}

Medical field is rapidly developing in Sri Lanka adding many subspecialties. In addition the competitive and consumeristic trends in society seem to have engulfed the life of many doctors. Even though multiple parameters show positive aspects of life, professionals are daily facing more and more problems. So, it is high time to study the Burnout among the Sri Lankan doctors.

\subsection{Objectives}

The primary objective of the study was to find out the prevalence of the "Burnout" among doctors in the teaching hospitals in Galle district. The specific objectives were to search for the possible associations like demographic characteristics, specialty, use of alcohol and smoking among the doctors.

\section{Methodology}

All the eligible doctors employed in the teaching hospital Mahamodara and Karapitiya were invited to the study. But finally the main sample was selected from the Karapitiya hospital due to some practical reasons.

Categories or doctors that included were, $\mathrm{MO} / \mathrm{SHO}$, post graduate trainees, RHO's, HO's who has completed six months of their training.

Categories mentioned below were excluded, Consultants,
Administrative grade doctors and $\mathrm{HO}, \mathrm{s}$ who has not completed six months of their training.

Ethical clearance for the study will be obtained from the Ethics Committee of the Faculty of Medicine, University of Ruhuna.

The principal author collected all the data to ensure the completeness and the quality of data. The suitable date and a time selected to minimize the disturbance to the routine activities after communicating with the medical officers. Confidentiality ensured by obtaining the completed questionnaire into a box.

\subsection{Analysis}

There were sixteen questions in the questionnaire. Eight out of sixteen assess the exhaustion and rest does the disengagement. Each question has four answers and candidate has to select degree of agreement and score to the relevant answer is given as mentioned below.

Calculations were done separately in each of the two main categories. In both of these categories if the mean is more than 2.5 they were considered burnout in the proper study [3].

All data coded and entered into a database, which created using the Statistical Package of Social Science (SPSS). Data cleaning and checking will be done. Where appropriate, data expressed as means and standard deviations. Differences between proportions of groups tested for statistical significance using the chi square test. Probability values less than 0.05 will be considered as statistically significant.

We added few extra questions at introduction to the original questionnaire in view of analyzing few more possible associations of Burnout.

\section{Results}

Table 3.1. Job specific factors of study participants

\begin{tabular}{lll}
\hline Variable & Number & Percentage \\
\hline Designation & & \\
HO & 23 & $14.8 \%$ \\
RHO/ SHO/MO & 98 & $63.2 \%$ \\
PG Trainees & 33 & $21.3 \%$ \\
Others & 1 & $0.7 \%$ \\
Working Experience & & \\
$<5$ years & 58 & $37.4 \%$ \\
$5-10$ years & 57 & $36.8 \%$ \\
11-15 years & 26 & $16.8 \%$ \\
$>15$ years & 14 & $9.0 \%$ \\
Specialty & & \\
Medicine & 25 & $19.1 \%$ \\
Surgery & 26 & $19.8 \%$ \\
GYN/OBS & 4 & $3.1 \%$ \\
Anesthesia/ETC/ICU & 17 & $13.0 \%$ \\
Others & 59 & $45.0 \%$ \\
Engage in private practice & & \\
Yes & 37 & $24.2 \%$ \\
No & 116 & $75.8 \%$ \\
\hline
\end{tabular}

155 doctors working in Teaching hospital Karapitiya and Teaching hospital Mahamodara have participated in the study.

First we analyzed the demographic factors of the participants according to gender, marital status and 
accommodation. Majority $(53.5 \%)$ of the participants was males and large majority (78.1\%) was married. Most of the doctors $(60.0 \%)$ are coming to work from their homes.

Analysis of the candidates for their relationship with colleagues and bosses reveled Large majority of the doctors had satisfactory relationship with their boss (94.7\%) and with their colleagues $(98.6 \%)$.

The use of alcohol and the smoking status also questioned. Most of the doctors has never consumed alcohol (73.7\%) and never smoked (93.5\%).

Some of important analysis which showed significant results is given in tables below.

\subsection{Job Specific Factors of Study Participants}

Most of doctors (63.2\%) were grade medical officers (RHO/SHO/MO). Only $25.8 \%$ had more than 10 years of working experience. Large majority $(75.8 \%)$ of doctors were not engaged in private practice.

\subsection{Prevalence of Exhaustion, Disengagement and Burnout among Study Participants}

Table 3.2. Prevalence of Exhaustion, Disengagement and Burnout among study participants

\begin{tabular}{lll}
\hline Variable & Number & Percentage \\
\hline Exhaustion & & \\
Yes & 56 & $36.1 \%$ \\
No & 99 & $63.9 \%$ \\
Disengagement & & \\
Yes & 53 & $34.2 \%$ \\
No & 102 & $65.8 \%$ \\
Burnout & & \\
Yes & 32 & $20.6 \%$ \\
No & 123 & $79.4 \%$ \\
\hline
\end{tabular}

$20.6 \%$ of doctors were identified as having burnout.

\subsection{Correlates of Burnout among Study Participants}

Table 3.3. Correlates of Burnout among study participants

\begin{tabular}{llll}
\hline Variable & Burnout & No Burnout & Significance \\
\hline Gender & 21 & 62 & Chi-square 2.3 \\
Male & 11 & 61 & $\mathrm{P}=0.12$ \\
Female & & & \\
Marital status & 25 & 96 & Chi-square 0.4 \\
Married & 7 & 27 & $\mathrm{P}=0.83$ \\
Unmarried & & & \\
Accommodation & 19 & 74 & Chi-square 1.2 \\
$\begin{array}{l}\text { Home } \\
\text { Boarded }\end{array}$ & 6 & 31 & $\mathrm{P}=0.5$ \\
$\begin{array}{l}\text { Quarters } \\
\text { Working Experience }\end{array}$ & 7 & 18 & \\
$\begin{array}{l}\text { Up to 10 years } \\
\text { More than 10 years }\end{array}$ & 10 & 30 & $\mathrm{Chi}$-square \\
$\begin{array}{l}\text { Private practice } \\
\text { Doing private practice }\end{array}$ & 12 & 25 & $\mathrm{P}=0.4$ \\
$\begin{array}{l}\text { Not doing private practice } \\
\text { Consumption of alcohol }\end{array}$ & 20 & 96 & Chi-square 3.9 \\
Never consumed & 18 & 94 & $\mathrm{P}=0.04$ \\
Consumed (current or past) & 14 & 26 & Chi-square \\
\hline
\end{tabular}

\section{Discussion}

The numbers of participants were 155 in the study. Majority $(53.5 \%)$ of the participants was males and large majority $(78.1 \%)$ was married. Most of doctors $(63.2 \%)$ were grade medical officers (RHO/SHO/MO). only 37 of them $(24.1 \%)$ were engaged in private practice.

Most of the doctors has never consumed alcohol (73.7\%) and never smoked (93.5\%).

The OLBI questionnaire assesses exhaustion and the disengagement as two main components of the Burnout. We found that among 155 of the participants 56 doctors (36.1\%) were exhausted and the 53 doctors $(34.2 \%)$ were disengaged. Finally the 32 doctors $(20.6 \%)$ were found burnout.

Some of the results found during literature search are mentioned below shows the gravity of the problem. Multiple studies have indicated a high prevalence of burnout among practicing physicians and have shown that one-third of physicians have experienced burnout at certain points throughout their careers (6). They describe it as that "Burnout" begins to cultivate its seeds during the medical school days, continues throughout the residency period, and finally matures in the daily life of practicing physicians. Studies suggest that the prevalence of burnout among medical students ranges between 31 and 49.6\% (7). Among residents, $50 \%$ and $76 \%$ of surgical and internal medicine residents are affected, respectively (8). Cohen et al. found that at least one-third of Canadian medical residents from different specialties experience a stressful life (9). On the contrary, Lagasse et al. report that $12.5 \%$ of medical residents scored positively on the three dimensions altogether (10). Even higher rates were recorded in a study done among Lebanese residents (11).

The above results highlight that at least over one third $(>30 \%)$ of the resident doctors are having features of burnout. Comparatively our results show some lower rate of burnout. We think that one reason could be since our medical practice has not reached up to the level where these results were found. There may other reasons like higher levels of tolerability of stressors like our people did during the post tsunami period. Though the overall burnout percentage is comparatively lower than many other countries this sample will not represents the whole country. The rapid development and the grooving higher demand for work in the medical profession will definitely affect these figures. More and more doctors are engaged in the private practice at the periphery, so need to evaluate the burnout among them for further elaboration of the issue. So these results may represent the iceberg phenomenon of the true figures of the issue. Finally we feel this result is a red flag to tackle the problem at the nip of the bud.

During the sub-group analysis we found that gender, marital status, accommodation or working experience did not show significant association with the Burnout. But we found that two other categories heaving significant association. Statistically significant number of burnout doctors were engaged in private practice $(\mathrm{p}=0.04)$ and similarly uses 
alcohol $(p=0.01)$. According to the statistics only 37 were involved in private practice. Also the number of alcohol users was 40 Out the 155 doctors.

Also the association of alcohol and the Burnout made the puzzle that what is the cause and the effect. There were no studies found done to assess the relation of the alcohol and the burnout. So there we need further detailed study.

This we think is an alarming result opening the eye for a need of more widespread study in the field.

Burnout among doctors is a common serious entity with devastating personal and professional consequences. Many studies have been done and multiple approaches made to relieve the burden (12) multidisciplinary actions that include changes in the work environmental factors along with stress management programs that teach people how to cope better with stressful events showed promising solutions to manage burnout. However, up until now, there have been no rigorous studies that prove this.

More interventional research targeting medical students, residents and practicing physicians are needed in order to improve psychological well-being, professional career enjoyment as well as the quality of care provided to patients.

\section{References}

[1] Schaufeli, W.B. and Enzmann, D. (1998), The Burnout Companion to Study and Research: A Critical Analysis, Taylor \& Francis, London.

[2] Halbesleben, J.R.B. and Buckley, M.R. (2004), "Burnout in organizational life", Journal of Management, Vol. 30, pp. 85979.

[3] Maslach, C., Jackson, S.E. and Leiter, M.P. (1996), MBI: The Maslach Burnout Inventory: Manual, Consulting
Psychologists Press, Palo Alto, CA.

[4] Kulkarni, G.K. (2006), "Burnout (Editorial)", Indian Journal of Occupational and Environmental Medicine, Vol. 10, pp. 3-4.

[5] Evangelia Demerouti, Arnold B. Bakker, Friedhelm Nachreiner, Wilmar B Schaufeli. The job Demands Resources Model of Burnout. Journal of Applied Psychology 2001; 86(3): 499-512.

[6] Shanafelt TD, Sonja B, Litjen T, Dyrbye LN, Sotile W, Daniel $\mathrm{S}$, et al. Burnout and satisfaction with work-life balance among US physicians relative to the general US population. JAMA Intern Med. 2012; 172: 1377-85. [PubMed].

[7] Dyrbye LN, Massie FS, Jr, Eacker A, Harper W, Power D, Durning SJ. Relationship between burnout and professional conduct and attitudes among US medical students. JAMA. 2010; 304: 1173-80. [PubMed]

[8] Shanafelt TD. Enhancing meaning in work: a prescription for preventing physician burnout and promoting patient-centered care. JAMA. 2009; 302: 1338-40. [PubMed]

[9] Cohen JS, Leung Y, Fahey M, Hoyt L, Sinha R, Cailler L, et al. The happy docs study: a Canadian Association of Interns and Residents well-being survey examining resident physician health and satisfaction within and outside of residency training in Canada. BMC Res Notes. 2008; 1: 105. [PMC free article] [PubMed]

[10] Legassie J, Zibrowski E, Goldszmidt M. Measuring resident well-being: impostorism and burnout syndrome in residency. $\mathrm{J}$ Gen Intern Med. 2008; 23: 1090-4. [PMC free article] [PubMed]

[11] Ashkar K, Romani M, Musharrafieh U, Shaaya M. Prevalence of burnout syndrome amongBurnout, anxiety, depression, and social skills in medical residents.

[12] Williams D1, Tricomi G, Gupta J, Janise A.Efficacy of Burnout Interventions in the Medical Education Pipeline.Acad psychiatry, 2014;07;18.pubMed. 